\title{
DESENVOLVIMENTO DE MUDAS DE MARACUJAZEIRO-AZEDO ENXERTADAS EM ESPÉCIES SILVESTRES DE Passiflora $^{1}$
}

\author{
MARCOS ANTONIO DELL'ORTO MORGADO ${ }^{2}$, CLAUDIO HORST BRUCKNER ${ }^{3}$, \\ LUCIANA DOMICIANO SILVA ROSADO ${ }^{3}$, CARLOS EDUARDO MAGALHÃES DOS SANTOS ${ }^{3}$
}

RESUMO - O maracujazeiro-azedo é acometido por diversas doenças, sendo que as do sistema radicular tendem a inviabilizar o cultivo em diversas regiões; entretanto, há espécies de Passifloras que se demonstram resistentes, sendo que tornam necessários estudos sobre a influência pela enxertia destas espécies no maracujazeiro-azedo. Portanto, objetivou-se estudar a viabilidade da enxertia e o desenvolvimento inicial de maracujazeiro-azedo (Passiflora edulis) enxertado sobre P. alata, P. cincinnata, P. edulis, P. gibertii, P. morifolia e $P$. mucronata, comparadas com $P$. edulis não enxertado, proveniente de sementes. Aos 60 dias após a semeadura, foi realizada a enxertia por garfagem e, por um período de 105 dias, avaliaram-se a sobrevivência dos enxertos, altura da planta, comprimento dos internódios, número de folhas, diâmetro do porta-enxerto e do enxerto, área foliar e a massa da matéria seca da parte aérea e das raízes. A sobrevivência da enxertia foi superior a $90 \%$, exceto na combinação $P$. edulis/P. morifolia que não apresentou brotações do enxerto e, posteriormente, morreram. A combinação $P$. edulis/P. gibertii tiveram menor altura do que $P$. edulis/P. mucronata, porém com semelhante número de folhas, demonstrando que o $P$. gibertii teve efeito ananizante, devido à redução do comprimento dos internódios. O maior diâmetro do enxerto foi apresentado por $P$. edulis/P. edulis, indicando maior compatibilidade de enxertia dentro da mesma espécie. Dentre as espécies silvestres utilizadas como porta-enxerto, $P$. mucronata proporcionou maior desenvolvimento da parte aérea.

Termos para indexação: Passiflora edulis, propagação, enxertia, produção de mudas.

\section{DEVELOPMENT OF PASSION FRUIT GRAFTED ON Passiflora WILD SPECIES}

\begin{abstract}
Various diseases affect sour passion fruit (Passiflora edulis) crop. The root system diseases limit the cultivation in different areas. Passiflora wild species are considered resistant or tolerant root diseases of passion fruit. The use of resistant species as rootstocks is a goal to overcome the disease problems. The study of growth and horticultural performance of Passiflora edulis grafted over wild Passiflora species are important to support the adoption of grafted plants in the orchards. This research studied the feasibility of grafting and the early growth of sour passion fruit grafted on P. alata, P. cincinnata, P. edulis, P. gibertii, $P$. morifolia, and P. mucronata, compared with $P$. edulis seedlings. The plants were grafted 60 days after sowing the seeds of the rootstocks. The experiment was evaluated for 105 days. The evaluated traits were scion survival, plant height, internode length, number of leaves, diameter of the rootstock and scion, leaf area and dry weight of shoots and roots. The scion survival was over $90 \%$, except over $P$. morifolia, which did not issue shoots and the plant perished soon after. P. edulis/P. gibertii had lower height than P. edulis/P. mucronata, but similar number of leaves, demonstrating dwarf effect of $P$. gibertii due to reduced internodes. P. edulis/P.edulis had the largest scion diameter, indicating higher grafting compatibility within the same species. Among the wild species, $P$. mucronata used as rootstock provided greater shoot growth.
\end{abstract}

Index terms: Passiflora edulis, propagation, grafting, seedling production.

${ }^{1}$ (Trabalho 099-14). Recebido em: 27-03-2014. Aceito para publicação em: 19-09-2014.

${ }^{2}$ Instituto Federal do Espírito Santo, Campus Itapina, CEP 29709-910, Colatina-ES. E-mail: agrodellorto@yahoo.com.br.

${ }^{3}$ Universidade Federal de Viçosa, Departamento de Fitotecnia, Avenida P.H. Rolfs, s/n, CEP 36570-900, Viçosa-MG. E-mail: bruckner@ufv.br, luciana.rosado@ufv.br, carlos.magalhaes@ufv.br. 


\section{INTRODUÇÃO}

O Brasil é o maior produtor e consumidor de maracujá-azedo (Passiflora edulis) do mundo. Possui uma área cultivada de aproximadamente 62 mil ha, com produção total de 920 mil toneladas anuais, caracterizando produtividade média de $15 \mathrm{t} /$ ha (IBGE, 2010). Embora a propagação vegetativa, principalmente a enxertia, seja regra na maioria das frutíferas, no maracujazeiro-azedo predomina a propagação por via seminífera. As razões pelas quais se realiza a enxertia, como redução do período juvenil, com maior precocidade de produção, redução do porte da planta e propagação de genótipos selecionados, não tem justificado a enxertia em maracujazeiro. $\mathrm{O}$ maracujazeiro é naturalmente precoce e ocupa espaço conforme o sistema de condução adotado e não pode ter a mesma uniformidade do que outras espécies em virtude da autoincompatibilidade (SUASSUNA et al., 2003) e da especificidade de polinizadores (SILVA et al., 1999).

Apresenta-se como justificativa para a propagação por enxertia o uso de porta-enxertos resistentes a doenças e capazes de prover boa adaptação ao solo e boa interação com variedadescopa para proporcionar alta produtividade, alta qualidade de frutos e a necessária longevidade da planta. Ainda não estão disponíveis porta-enxertos com as características mencionadas (RONCATTO et al., 2011).

As principais doenças que atacam o sistema radicular do maracujazeiro-azedo são a murcha de fusarium causada pelo fungo Fusarium oxysporum f. sp. passiflorae e a morte prematura de plantas que está associada a fungos do solo, como Fusarium oxysporum f. sp. passiflorae, Fusarium solani e Phytophthora spp.. Em decorrência destes problemas fitossanitários, muitos pomares comerciais de maracujazeiro-azedo têm sido renovados a cada dois anos ou mesmo anualmente, com necessária mudança da área de plantio constantemente (RONCATTO et al., 2004; CAVICHIOLI et al., 2011a). Junqueira et al. (2003) verificaram que, em 11 cultivares comerciais testadas, todas foram suscetíveis à virose do endurecimento do fruto, bacteriose, antracnose, verrugose e septoriose, com pouca variabilidade. Doenças da parte aérea, como antracnose, verrugose e septoriose, têm sido controladas principalmente com aplicação de fungicidas (MEDEIROS;PERUCH, 2012). Trabalhos buscando resistência genética têm sido efetuados para bacteriose (KOSOSKI et al., 2008; FLORES et al., 2012), verrugose (SANTOS et al., 2008) e viroses (FERREIRA et al., 2010). A resistência à fusariose tem sido buscada dentro de $P$. edulis (FLORES et al., 2012), bem como em espécies silvestres (JUNQUEIRA et al., 2006).

A introgressão de genes de resistência de espécies silvestres pode ser possível em alguns casos por meio de hibridação (JUNQUEIRA et al., 2008), embora os híbridos interespecíficos nem sempre sejam férteis (WIDMER et al., 2009) para se continuar a realizar retrocruzamentos para a espécie cultivada. As espécies silvestres resistentes a doenças do sistema radicular poderão ser usadas diretamente como porta-enxertos (CAVICHIOLI et al., 2009), desde que reúnam qualidades fitotécnicas necessárias a um bom porta-enxerto, ou na constituição de porta-enxertos híbridos interespecíficos, nos quais a fertilidade pode não ser essencial, se forem propagados vegetativamente.

Roncatto et al. (2004) verificaram que mudas de $P$. gibertti e $P$. nitida mostraram-se resistentes aos fungos de solo, sem apresentar mortalidade, enquanto as plantas da espécie $P$. edulis sofreram mortalidade de $100 \%$ na maioria das variedades, ocorrendo a morte dos dois meses até aos dois anos do plantio. Cavichioli et al. (2011b) também verificaram que após 12 meses do plantio no campo ocorreu morte prematura de $91,4 \%$ das plantas da espécie $P$. edulis enxertadas sobre a mesma espécie, enquanto a mortalidade foi de apenas $9,0 \% \mathrm{em}$ plantas enxertadas sobre $P$. gibertti, o qual apresentou tolerância ao fungo Fusarium solani e ao nematoide Rotylenchulus reniformis, que estavam presentes no solo, causando a morte das plantas suscetíveis.

Vários testes têm sido realizados para o maracujazeiro-azedo buscando resistência a doenças de solos em espécies silvestres de Passiflora (MENEZES et al., 1994; RONCATTO et al., 2004; CAVICHIOLI et al., 2011b), além de testarem a metodologia e a compatibilidade da enxertia de $P$. edulis sobre estas espécies (CHAVES et al., 2004; JUNQUEIRA et al., 2006; CAVICHIOLI; CORRÊA, 2009; CAVICHIOLI et al., 2009; LENZA et al., 2009; NOGUEIRA FILHO et al., 2010; CAVICHIOLI et al., 2011a,b; RONCATTO et al., 2011). Como, além da resistência a doenças, os porta-enxertos devem ter qualidades fitotécnicas adequadas, mais trabalhos devem ser realizados visando a auxiliar na escolha ou no desenvolvimento de porta-enxertos para $P$. edulis, avaliando o potencial de outras espécies silvestres como porta-enxertos e o desenvolvimento das mudas enxertadas.

Portanto, objetivou-se verificar a compatibilidade e o desenvolvimento inicial de mudas de maracujazeiro-azedo (Passiflora edulis) enxertadas em espécies silvestres de Passiflora, para subsidiar a seleção de porta-enxertos. 


\section{MATERIAL E MÉTODOS}

O trabalho foi desenvolvido de janeiro a agosto de 2011, em ambiente protegido, na Universidade Federal de Viçosa (UFV), em Viçosa (MG), visando a estudar seis espécies como portaenxertos do maracujazeiro-azedo (P. edulis): $P$. alata, P. cincinnata, $P$. edulis, $P$. gibertii, $P$. morifolia e P. mucronata. Como tratamento-testemunha, foi utilizado o $P$. edulis não enxertado, proveniente de sementes.

Sementes das referidas espécies foram colocadas a germinar em recipientes plásticos com capacidade para $0,5 \mathrm{~L}$. O substrato constituiu-se de mistura de solo corrigido quanto à acidez e fertilizado, areia e esterco na proporção $3: 1: 1$, tendo a mistura as seguintes características químicas: $\mathrm{P}$ $=1,15 ; \mathrm{K}=2,60 ;\left(\right.$ todos em $\mathrm{cmol} \cdot \mathrm{dm}^{-3}$ - Extrator Mehlich); $\mathrm{Ca}^{+2}=6,87 ; \mathrm{Mg}^{+2}=1,62 ; \mathrm{Al}^{+3}=0,00$; (todos $\mathrm{cmol}_{\mathrm{c}} \cdot \mathrm{dm}^{-3}-$ Extrator $\left.\mathrm{KCl}\right) ; \mathrm{pH}\left(\mathrm{H}_{2} \mathrm{O}\right)=$ 5,$96 ; \mathrm{H}+\mathrm{Al}=4,20\left(\mathrm{cmol}_{\mathrm{c}} \cdot \mathrm{dm}^{-3}-\right.$ Extrator: Acetato de Cálcio); $\mathrm{SB}=15,16 ; \mathrm{t}=15,16 ; \mathrm{T}=19,36 ;($ Todos $\left.\mathrm{cmol}_{\mathrm{c}} \cdot \mathrm{dm}^{-3}\right) ; \mathrm{V}=78,30 \% ; \mathrm{m}=0,0 \%$.

Após a germinação, realizou-se desbaste, deixando apenas uma planta por recipiente. Decorridos 60 dias após a semeadura, foi realizada a enxertia do tipo fenda cheia a $10 \mathrm{~cm}$ do colo da planta. Os garfos, com dois nós, foram retirados na porção mediana dos ramos de uma mesma planta adulta de maracujazeiro-azedo proveniente do programa de melhoramento genético da UFV. Logo após a realização da enxertia, o enxerto foi coberto com sacola plástica incolor, a fim de formar uma câmara úmida e reduzir a desidratação do enxerto, sendo retirada quando iniciaram as primeiras brotações do enxerto.

Aos quinze dias após a enxertia, foi analisada a porcentagem de sobrevivência dos enxertos, avaliando-se a presença de brotações, no delineamento inteiramente ao acaso, com cinco repetições, constituindo 30 parcelas com 20 plantas por parcela.

Após esta avaliação, promoveu-se a seleção das oito melhores plantas quanto ao aspecto visual e ausência de doenças por tratamento, que foram transplantadas para vaso de polietileno de dez litros com o mesmo substrato mencionado anteriormente, conduzidas em haste única e tutoradas com auxílio de cordão até o fio de aço, localizado a 2 metros de altura.

Foram analisadas as características: altura, comprimento dos internódios e número de folhas, em quatro avaliações (aos 15; 45; 75 e 105 dias após a enxertia); diâmetro do porta-enxerto e do enxerto, em três avaliações (aos 45; 75 e 105 dias após a enxertia); área foliar e a massa da matéria seca da parte aérea e da raiz, na avaliação final (aos 105 dias após a enxertia). A altura da planta foi mensurada, utilizando régua com $1 \mathrm{~mm}$ de precisão, medindo-se a planta do colo ao ápice; o diâmetro do porta-enxerto foi medido a $5 \mathrm{~cm}$, e o diâmetro do enxerto acerca de $12 \mathrm{~cm}$ acima do colo da muda, com paquímetro digital de $0,001 \mathrm{~mm}$ de precisão. $\mathrm{O}$ comprimento dos internódios foi obtido pela relação altura/número de folhas, considerando que cada axila de folha representa um nó.

O delineamento estatístico foi o inteiramente ao acaso, com sete tratamentos e oito repetições, consistindo em 56 parcelas. A parcela foi representada por uma planta alocada em vaso de polietileno de dez litros. Os dados obtidos foram submetidos à análise de variância, e as médias foram comparadas pelo teste de Tukey $(p<0,05)$, utilizando-se do programa estatístico SAS (Sas Institute INC., NC, USA, 2004). Os dados de número de folhas foram transformados por $\sqrt{\mathrm{X}}$, antes das análises estatísticas.

\section{RESULTADOS E DISCUSSÃO}

A porcentagem de sobrevivência dos enxertos aos 15 dias após a enxertia foi superior a 90\% para todas as espécies estudadas (Tabela 1), com exceção da combinação $P$. edulis/P. morifolia que não apresentou brotações do enxerto, sendo observada soldadura entre enxerto e porta-enxerto, mas, após um período de aproximadamente 30 dias, as plantas apresentaram clorose severa, e aos 40 dias após a enxertia, as plantas morreram. Este resultado demonstra que a espécie $P$. morifolia não pode ser utilizada como porta-enxerto de $P$. edulis, pois esta combinação mostrou-se incompatível.

Diversos autores demonstraram baixo índice de pegamento de enxertia de cultivares de maracujazeiro-azedo (P. edulis) sobre porta-enxertos de espécies silvestres. O pegamento foi de $42 \%$ da cultivar 'Rubi' sobre $P$. actinia (CHAVES et al., 2004), de 30,6\% da cultivar 'FB 200' sobre $P$. setacea (NOGUEIRA FILHO et al., 2011) e de $25 \%$ da cultivar 'FB 100' sobre $P$. alata (RONCATTO et al., 2011).

Não foram encontrados relatos de incompatibilidade da combinação $P$. edulis/P. morifolia na literatura. Mesmo havendo a soldadura no local da enxertia, pode posteriormente não haver boa conexão entre os vasos vasculares, devido a diversos fatores, tais como reguladores de crescimento e translocação de proteínas; conforme revisado por Pina e Errea (2005). 
Comparando-se a altura de $P$. edulis/ $P$. edulis com $P$. edulis não enxertado (Tabela 2), verificou-se que os dois tratamentos só diferiram significativamente entre si na segunda avaliação (45 dias), indicando que a prática da enxertia, em si, não influenciou significativamente no crescimento e, consequentemente, na altura das plantas. Na enxertia de $P$. edulis sobre outras espécies, destaca-se o tratamento enxertado em $P$. mucronata, seguido de $P$. cincinnata, nas datas mais tardias de avaliação. A combinação $P$. edulis/P. mucronata não se destacou apenas aos 75 dias após a enxertia (DAE), mas recuperou o crescimento na última avaliação.

As combinações utilizando os porta-enxertos $P$. gibertii e $P$. alata apresentaram menor altura da parte aérea, a partir da terceira avaliação (75 dias), sendo que aos 105 dias a diferença da combinação utilizando o porta-enxerto $P$. gibertii se acentuou, seguida pelo $P$. alata. Plantas com maior crescimento da parte aérea são desejáveis, desde que esta característica seja convertida em aumento de produtividade, sem aumentar o período juvenil e sem comprometer o custo de produção.

Preconiza-se que as mudas de maracujá apresentem, no mínimo, $15 \mathrm{~cm}$ de altura por ocasião do plantio (NOGUEIRA FILHO et al., 2011). Neste trabalho, as mudas enxertadas estariam adequadas para o plantio, aproximadamente aos 105 dias após a semeadura, ou seja, 60 dias até a enxertia e 45 dias após a enxertia (DAE), com exceção das mudas de $P$. edulis/P. alata e P. edulis/P. edulis. Normalmente, as mudas produzidas por sementes necessitam de 60 a 90 dias após a semeadura para atingirem a altura de $15 \mathrm{~cm}$. Lenza et al. (2009), testando outras espécies como porta-enxertos, obtiveram maiores alturas com a enxertia sobre $P$. edulis, acesso Piratininga e cultivar FB 200, porém o tempo foi superior a 105 dias. O tempo de formação da muda, em si, não deve ser encarado como empecilho à produção de mudas enxertadas, pois não foi substancialmente maior do que demora a formação das mudas convencionais provenientes de sementes, desde que a enxertia consiga incorporar resistência a doenças, mantendo ou aumentando a produtividade e a qualidade de frutos.

A enxertia induziu maior comprimento dos internódios no maracujazeiro-azedo, já que o $P$. edulis/P. edulis apresentou valores maiores do que o $P$. edulis não enxertado para esta característica (Tabela 2). O comprimento dos internódios das combinações $P$. edulis/P. mucronata e $P$. edulis/ $P$. edulis foi superior às demais combinações e ao $P$. edulis não enxertado, aos 105 DAE.

A combinação $P$. edulis/P. gibertii apresentou valores de altura de plantas e comprimento dos internódios menores que $P$. edulis/P. mucronata, porém não apresentou diferenças significativas quanto ao número de folhas (Tabela 2), o que indica que o $P$. gibertii induziu efeito ananizante devido à redução do comprimento dos internódios quando utilizado como porta-enxerto do $P$. edulis. Cavichioli et al. (2011b) também verificaram que mudas de maracujazeiro-azedo ( $P$. edulis) enxertadas sobre $P$. gibertii tiveram menor desenvolvimento da planta em relação à enxertia sobre $P$. edulis. Porém, não houve diferenças significativas no número de frutos e na produtividade por hectare entre os citados tratamentos. Os autores citaram que a vantagem de utilizar $P$. gibertii como porta-enxerto foi a sobrevivência de $91 \%$ das mudas, em comparação à sobrevivência de $8,6 \%$ das mudas enxertadas sobre $P$. edulis, cultivadas em solo contaminado por fungos causadores da morte prematura das plantas. Por outro lado, em solo não contaminado, Cavichioli et al. (2011a) verificaram que plantas enxertadas sobre $P$. gibertii apresentaram menor vigor, menor crescimento vegetativo, frutos com menor massa e menor produtividade.

Nogueira Filho et al. (2005) descreveram que o número de folhas é uma característica que, no maracujazeiro, pode sofrer muitas variações devido a fatores não controlados, sendo necessário, conforme Lenza et al. (2009), acrescentar outras características de crescimento e desenvolvimento de plantas, como o número de internódios, uma vez que o número de folhas é condicionado pelo número de nós. A combinação $P$. edulis/ $P$. gibertii apresentou a menor altura e o menor comprimento dos internódios, porém semelhante número de folhas que as demais combinações, o que pode ser atribuído ao menor número de internódios, mas com valores aproximados de número de internódios, pela relação altura/comprimento dos internódios, com a combinação $P$. edulis/ $P$. edulis, que apresentou o maior comprimento dos internódios. O menor comprimento dos internódios pode ser útil num eventual interesse por plantas mais compactas.

Lenza et al. (2009), em estudos sobre o efeito de passifloras silvestres como porta-enxerto para $P$. edulis, observaram que a espécie $P$. gibertii proporcionava um maior número de internódios em relação às demais espécies silvestres estudadas $(P$. coccinea, $P$. giberti, $P$. alata, $P$. quadrangulares e $P$. nitida), utilizadas como porta-enxerto.

O diâmetro do caule, medido na região do porta-enxerto (5 $\mathrm{cm}$ do colo), foi maior em $P$. edulis/P. edulis durante todo o período avaliado. Plantas enxertadas sobre os porta-enxertos $P$. 
alata e $P$. cincinnata, aos 45 DAE, não diferiram significativamente das que utilizavam $P$. gibertii e $P$. edulis não enxertado. Aos $75 \mathrm{DAE}, P$. edulis/ $P$. edulis apresentou diâmetro superior aos demais tratamentos, que não diferiram entre si. $P$. edulis/ $P$. alata, $P$. edulis/P. gibertii e P. edulis/P. mucronata não diferiram entre si quanto ao diâmetro do portaenxerto, aos 105 DAE. P. edulis/P. mucronata também não diferiu do $P$. edulis/ $P$. cincinnata, que por sua vez não diferiu do $P$. edulis não enxertado (Tabela 3). Cavichioli et al. (2011a) observaram que o diâmetro do caule medido na região do portaenxerto ( $1 \mathrm{~cm}$ do colo), aos 360 dias de idade, foi maior em $P$. alata $(37,43 \mathrm{~mm})$ do que $P$. edulis/ $P$. edulis e $P$. gibertii $(25,71 \mathrm{~mm})$. Entretanto, Nogueira Filho et al. (2010), utilizando o método de enxertia hipocotiledonar, observaram os mesmos valores de incremento em diâmetro do porta-enxerto nas espécies $P$. alata, $P$. edulis e $P$. gibertii, até os 60 dias após a enxertia.

Aos 45 DAE, as combinações $P$. edulis/P. cincinnata e o $P$. edulis/P. edulis apresentaram diâmetros do enxerto superiores aos da combinação P. edulis/P. alata, a qual não difere das demais (Tabela 3). A partir dos $75 \mathrm{DAE}$, as passifloráceas silvestres utilizadas como porta-enxerto não diferiram entre si, resultado também observado aos 105 dias após a enxertia. Sendo o diâmetro do caule da planta um indicativo de vigor (MENEZES et al., 1994; KIMURA, 1994), pode-se pressupor que plantas de $P$. edulis/P. edulis são mais vigorosas, além de notar que a combinação entre espécies diferentes é menos vigorosa. Os resultados obtidos corroboram os obtidos por Cavichioli et al. (2011b). Os maiores valores de diâmetro do enxerto apresentados pelo $P$. edulis/P. edulis podem ser devido à maior compatibilidade genética entre o enxerto e o portaenxerto, como já era esperado, por se tratar da mesma espécie, corroborando os resultados obtidos por Nogueira Filho et al. (2005). Esta compatibilidade genética pode ter possibilitado a união entre o enxerto e o porta-enxerto mais rápida e efetiva, que permitiu maior desenvolvimento inicial.

O crescimento diferenciado, induzido pelos porta-enxertos $P$. mucronata e $P$. gibertii, pode estar diretamente relacionado com o acúmulo de giberelina na parte aérea devido à prática da enxertia. $\mathrm{O}$ maior acúmulo de giberelina na parte aérea ( $P$. edulis), quando utilizado o P. mucronata como porta-enxerto, pode ser devido à menor translocação de giberelina da parte aérea para o sistema radicular. O local da enxertia pode estar afetando este fluxo, já que em $P$. edulis/P. edulis o comprimento dos internódios é superior ao $P$. edulis não enxertado (Tabela 2 ).
Deste modo, maiores valores de comprimento dos internódios apresentados pelo maracujazeiro-azedo quando enxertado sobre o P. mucronata podem ser devido a maiores concentrações de giberelinas endógenas na parte aérea, que, consequentemente, induziram maior atividade do meristema intercalar, localizado próximo à base.

Santos et al. (2010) relataram aumento do comprimento dos internódios do maracujazeiroazedo, e como consequência a altura, em decorrência de aplicações exógenas de giberelinas. Segundo Taiz e Zeiger (2004), as giberelinas estimulam tanto o alongamento celular quanto a divisão celular. No entanto, a ação das giberelinas foi mais pronunciada no alongamento celular, já que, apesar de o portaenxerto $P$. mucronata ter induzido maiores valores de altura (Tabela 2), comprimento dos internódios (Tabela 2) e área foliar (Tabela 4) do que o P. gibertii, os valores de massa da matéria seca da parte aérea e do sistema radicular não diferiram significativamente $(p>0,05)$ (Tabela 4).

Os porta-enxertos $P$. alata e $P$. gibertii proporcionaram os menores valores de área foliar do enxerto (Tabela 4), entretanto não diferiram significativamente dos demais quanto à massa da matéria seca da parte aérea, enquanto para massa seca do sistema radicular todos os porta-enxertos silvestres foram semelhantes, diferindo de P. edulis/P. edulis. 
TABELA 1 - Porcentagem de sobrevivência das plantas de maracujazeiro-azedo autoenxertadas e enxertadas sobre cinco espécies silvestres, aos 15 dias após a enxertia

\begin{tabular}{cccccc}
\hline \multicolumn{5}{c}{ Porcentagem de sobrevivência (\%) } \\
\hline P. edulis / P. edulis & P. alata & P. cincinnata & P. gibertii & P. mucronata & P. morifolia \\
\hline 95,0 A & $90,6 \mathrm{~A}$ & $92,1 \mathrm{~A}$ & $90,3 \mathrm{~A}$ & $94,3 \mathrm{~A}$ & $0,0 \mathrm{~B}$ \\
\hline
\end{tabular}

Médias seguidas pelas mesmas letras não diferem entre si, pelo teste de Tukey $(p<0,05)$.

TABELA 2 - Médias de altura, comprimento dos internódios e número de folhas das plantas de maracujazeiroazedo enxertadas sobre quatro espécies silvestres, autoenxertadas e não enxertas aos 15; 45; 75 e 105 dias após a enxertia (DAE)

\begin{tabular}{|c|c|c|c|c|c|}
\hline \multirow{2}{*}{ Características } & \multirow{2}{*}{ Enxertos } & \multicolumn{4}{|c|}{ Dias após à enxertia } \\
\hline & & 15 & 45 & 75 & 105 \\
\hline \multirow{7}{*}{ 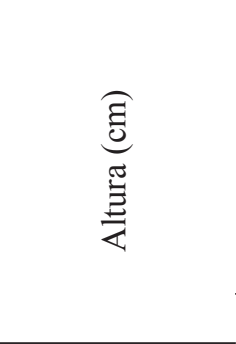 } & P. edulis não enxertado & $3,31 \mathrm{D}$ & $22,25 \mathrm{~B}$ & $85,56 \mathrm{AB}$ & $136,2 \mathrm{~B}$ \\
\hline & P. edulis/P.edulis & $3,79 \mathrm{CD}$ & $9,72 \mathrm{D}$ & $103,37 \mathrm{~A}$ & $161,0 \mathrm{~B}$ \\
\hline & P. edulis / P. alata & $6,06 \mathrm{AB}$ & $12,26 \mathrm{D}$ & $50,37 \mathrm{C}$ & $101,6 \mathrm{C}$ \\
\hline & P. edulis / P. cincinnata & $5,11 \mathrm{ABC}$ & $19,95 \mathrm{BC}$ & $101,56 \mathrm{~A}$ & $136,8 \mathrm{~B}$ \\
\hline & P. edulis / P. gibertii & $4,91 \mathrm{BCD}$ & $14,86 \mathrm{CD}$ & $45,25 \mathrm{C}$ & $64,6 \mathrm{D}$ \\
\hline & P. edulis / P. mucronata & $6,78 \mathrm{~A}$ & $35,34 \mathrm{~A}$ & $74,13 \mathrm{~B}$ & $195,8 \mathrm{~A}$ \\
\hline & CV $(\%)$ & 22,12 & 21,37 & 18,23 & 13,12 \\
\hline \multirow{7}{*}{ 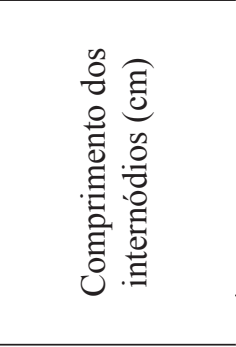 } & P. edulis não enxertado & $0,54 \mathrm{~B}$ & $2,02 \mathrm{~B}$ & $3,52 \mathrm{C}$ & $4,51 \mathrm{~B}$ \\
\hline & P. edulis/P.edulis & $1,41 \mathrm{~A}$ & $1,34 \mathrm{CD}$ & $6,22 \mathrm{~A}$ & $7,33 \mathrm{~A}$ \\
\hline & P. edulis / P. alata & $0,79 \mathrm{~B}$ & $1,19 \mathrm{D}$ & $2,82 \mathrm{C}$ & $4,02 \mathrm{~B}$ \\
\hline & P. edulis / P. cincinnata & $0,83 \mathrm{~B}$ & $1,87 \mathrm{BC}$ & $4,69 \mathrm{~B}$ & $4,88 \mathrm{~B}$ \\
\hline & P. edulis / P. gibertii & $0,78 \mathrm{~B}$ & $1,53 \mathrm{BCD}$ & $2,55 \mathrm{C}$ & $2,58 \mathrm{C}$ \\
\hline & P. edulis / P. mucronata & $0,92 \mathrm{~B}$ & $3,17 \mathrm{~A}$ & $3,37 \mathrm{C}$ & $6,58 \mathrm{~A}$ \\
\hline & CV $(\%)$ & 15,87 & 15,78 & 13,80 & 11,03 \\
\hline \multirow{7}{*}{ 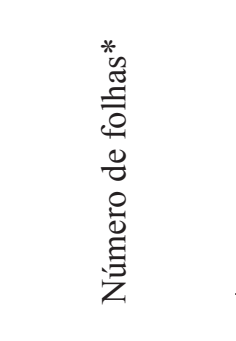 } & P. edulis não enxertado & $3,65 \mathrm{BC}$ & $4,36 \mathrm{~A}$ & $5,07 \mathrm{AB}$ & $5,59 \mathrm{ABC}$ \\
\hline & P. edulis/P.edulis & $3,63 \mathrm{C}$ & $3,93 \mathrm{~B}$ & $4,72 \mathrm{~B}$ & $5,29 \mathrm{C}$ \\
\hline & P. edulis / P. alata & $3,96 \mathrm{~A}$ & $3,90 \mathrm{~B}$ & $4,88 \mathrm{AB}$ & $5,47 \mathrm{ABC}$ \\
\hline & P. edulis / P. cincinnata & $3,77 \mathrm{ABC}$ & $4,07 \mathrm{AB}$ & $4,99 \mathrm{AB}$ & $5,33 \mathrm{BC}$ \\
\hline & P. edulis / P. gibertii & $3,84 \mathrm{AB}$ & $4,14 \mathrm{AB}$ & $5,14 \mathrm{~A}$ & $5,63 \mathrm{AB}$ \\
\hline & P. edulis / P. mucronata & $3,92 \mathrm{~A}$ & $4,18 \mathrm{AB}$ & $5,11 \mathrm{~A}$ & $5,74 \mathrm{~A}$ \\
\hline & $\mathrm{CV}(\%)$ & 15,44 & 19,62 & 15.03 & 10,55 \\
\hline
\end{tabular}

*Dados transformados. Médias seguidas pelas mesmas letras na coluna não diferem entre si, pelo teste de Tukey $(p<0,05)$. 
TABELA 3 - Médias do diâmetro do porta-enxerto e do enxerto, medidos a $5 \mathrm{~cm}$ e $12 \mathrm{~cm}$, respectivamente, do colo de plantas de maracujazeiro-azedo enxertadas sobre quatro espécies silvestres, autoenxertadas e não enxertadas aos 45; 75 e 105 dias após a enxertia (DAE)

\begin{tabular}{|c|c|c|c|c|}
\hline \multirow{2}{*}{ Características } & \multirow{2}{*}{ Espécies } & \multicolumn{3}{|c|}{ Dias após à enxertia } \\
\hline & & 45 & 75 & 105 \\
\hline \multirow{7}{*}{ 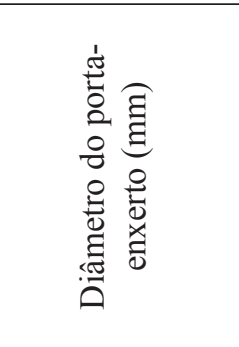 } & P. edulis não enxertado & $4,06 \mathrm{BC}$ & $3,98 \mathrm{~B}$ & $4,38 \mathrm{D}$ \\
\hline & P. edulis/P.edulis & $5,47 \mathrm{~A}$ & $6,57 \mathrm{~A}$ & $6,57 \mathrm{~A}$ \\
\hline & P. edulis / P. alata & $3,60 \mathrm{CD}$ & $3,97 \mathrm{~B}$ & $5,15 \mathrm{~B}$ \\
\hline & P. edulis / P. cincinnata & $3,71 \mathrm{CD}$ & $4,20 \mathrm{~B}$ & $4,41 \mathrm{CD}$ \\
\hline & P. edulis / P. gibertii & $3,50 \mathrm{D}$ & $4,21 \mathrm{~B}$ & $5,15 \mathrm{~B}$ \\
\hline & P. edulis / P. mucronata & $4,29 \mathrm{~B}$ & $4,60 \mathrm{~B}$ & $5,03 \mathrm{BC}$ \\
\hline & $\mathrm{CV}(\%)$ & 13,33 & 10,82 & 11,45 \\
\hline \multirow{6}{*}{ 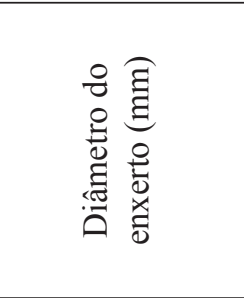 } & P. edulis/P.edulis & $4,64 \mathrm{~A}$ & $5,36 \mathrm{~A}$ & $6,45 \mathrm{~A}$ \\
\hline & P. edulis / P. alata & $3,83 \mathrm{~B}$ & $4,55 \mathrm{~B}$ & $5,03 \mathrm{~B}$ \\
\hline & P. edulis / P. cincinnata & $4,78 \mathrm{~A}$ & $4,94 \mathrm{AB}$ & $4,87 \mathrm{~B}$ \\
\hline & P. edulis / P. gibertii & $4,19 \mathrm{AB}$ & $4,57 \mathrm{~B}$ & $5,08 \mathrm{~B}$ \\
\hline & P. edulis / P. mucronata & $4,31 \mathrm{AB}$ & $4,61 \mathrm{~B}$ & $4,94 \mathrm{~B}$ \\
\hline & $\mathrm{CV}(\%)$ & 11,93 & 7,64 & 8,35 \\
\hline
\end{tabular}

Médias seguidas pelas mesmas letras na coluna não diferem entre si, pelo teste de Tukey $(p<0,05)$.

TABELA 4 - Médias da área foliar (AF), massa seca da parte aérea (MSPA) e massa seca da raiz (MSR) nas plantas de maracujazeiro-azedo enxertadas sobre quatro espécies silvestres, autoenxertadas e não enxertadas aos 105 dias após a enxertia (DAE)

\begin{tabular}{cccc}
\hline Espécies & $\mathbf{A F}\left(\mathbf{d m}^{2}\right)$ & MSPA (g) & MSR (g) \\
\hline P. edulis não enxertado & $1126,90 \mathrm{~A}$ & $12,45 \mathrm{~A}$ & $6,48 \mathrm{~B}$ \\
P. edulis / P. edulis & $1266,25 \mathrm{~A}$ & $16,36 \mathrm{~A}$ & $8,56 \mathrm{~A}$ \\
P. edulis / P. alata & $888,47 \mathrm{~B}$ & $9,67 \mathrm{~A}$ & $3,47 \mathrm{~B}$ \\
P. edulis / P. cincinnata & $1174,98 \mathrm{~A}$ & $9,65 \mathrm{~A}$ & $1,90 \mathrm{~B}$ \\
P. edulis / P. gibertii & $799,10 \mathrm{~B}$ & $9,62 \mathrm{~A}$ & $2,86 \mathrm{~B}$ \\
P. edulis / P. mucronata & $1256,46 \mathrm{~A}$ & $16,18 \mathrm{~A}$ & $4,61 \mathrm{~B}$ \\
\hline CV $(\%)$ & 25,05 & 23,38 & 25,23 \\
\hline
\end{tabular}

\section{CONCLUSÕES}

Todas as espécies silvestres de Passiflora testadas como porta-enxerto de maracujazeiroazedo ( $P$. edulis) proporcionaram pegamento de enxertia e bom desenvolvimento das mudas, com exceção da espécie $P$. morifolia, para a qual houve incompatibilidade, com morte das plantas enxertadas sobre esta espécie.

Dentre as espécies silvestres utilizadas como porta-enxerto, P. mucronata proporcionou maior desenvolvimento da parte aérea, enquanto a espécie $P$. gibertii induziu efeito ananizante ao maracujazeiro-azedo.

\section{AGRADECIMENTOS}

À Coordenação de Aperfeiçoamento de Pessoal de Nível Superior (CAPES), ao Conselho Nacional de Desenvolvimento Científico e Tecnológico (CNPq) e à Fundação de Amparo à Pesquisa do Estado de Minas Gerais (FAPEMIG), pela concessão da bolsa de estudos e auxílio financeiro; e ao Instituto Agronômico de Campinas, Embrapa e UESC, pelo fornecimento das sementes das espécies estudadas. 


\section{REFERÊNCIAS}

CAVICHIOLI, J.C.; CORRÊA, L. de S. Resultados da técnica de enxertia na produção de mudas de maracujazeiro-amarelo. 2009. Disponível em: <http://www.infobibos.com/Artigos/2009_2/ Maracuja/index.htm>. Acesso em: 23 ago. 2012.

CAVICHIOLI, J.C.; CORRÊA, L. de S.; BOLIANI, A.C.; OLIVEIRA, J.C. de. Uso de câmara úmida em enxertia hipocotiledonar de maracujazeiro-amarelo sobre três porta-enxertos. Revista Brasileira de Fruticultura, Jaboticabal, v.31, n.2, p.532-538, 2009.

CAVICHIOLI, J.C.; CORRÊA, L. de S.; BOLIANI, A.C.; SANTOS, P.C. dos. Desenvolvimento e produtividade do maracujazeiro-amarelo enxertado em três porta-enxertos. Revista Brasileira de Fruticultura, Jaboticabal, v.33, n.2, p.558-566, $2011 \mathrm{a}$

CAVICHIOLI, J.C.; CORREAA, L. de S.; GARCIA, M. J. de M.; FISCHER, I. H. Desenvolvimento, produtividade e sobrevivência de maracujazeiroamarelo enxertado e cultivado em área com histórico de morte prematura de plantas. Revista Brasileira de Fruticultura, Jaboticabal, v.33, n.2, p.567-574, $2011 b$.

CHAVES, R.C.; JUNQUEIRA, N.T.V.; MANICA, I.; PEIXOTO, J.R.; PEREIRA, A.V.; FIALHO, J. de F. Enxertia de maracujazeiro-azedo em estacas herbáceas enraizadas de espécies de passifloras nativas. Revista Brasileira de Fruticultura, Jaboticabal, v.26, n.1, p.120-123, 2004.

FERREIRA, S.S.; BARROS, D.R.; ALMEIDA, M.R. de; ZERBINI, F.M. Characterization of Passionfruit severe leaf distortion virus, a novel begomovirus infecting passionfruit in Brazil, reveals a close relationship with tomato-infecting begomoviruses. Plant Pathology, Oxford, v.59, n.2, p.221-230, 2010.

FLORES, P.S.; OTONI, W.C.; DHINGRA, O.D.; DINIZ, S.P.S. de; SANTOS, T.M. dos; BRUCKNER, C.H. In vitro selection of yellow passion fruit genotypes for resistance to Fusarium vascular wilt. Plant Cell, Tissue and Organ Culture, Dordrecht, v.108, n.1, p.37-45, 2012.
IBGE. Produção Agrícola Municipal. 2010.

Disponível em: <http://www.sidra.ibge.gov.br/bda/ agric/default.asp > . Acesso em: 23 abr. 2013.

JUNQUEIRA, K.P.; FALEIRO, F.G.; JUNQUEIRA, N.T.V.; BELLON, G.; RAMOS, J.D.; BRAGA, M.F.; SOUZA, L.S. de. Confirmação de híbridos interespecíficos artificiais no gênero Passiflora por meio de marcadores RAPD. Revista Brasileira de Fruticultura, Jaboticabal, v.30, n.1, p.191-196, 2008.

JUNQUEIRA, N.T.F.; ANJOS, J.R.N. dos; SILVA, A.P. de O.; CHAVES, R. da C.; GOMES, A.C. Reação às doenças e produtividade de onze cultivares de maracujá-azedo cultivados sem agrotóxicos. Pesquisa Agropecuária Brasileira, Brasília, v.38, n. 8, p.1005-1010, 2003.

JUNQUEIRA, N.T.F.; LAGE, D.A. da C.; BRAGA, M.F.; PEIXOTO, J.R.; BORGES, T.A.; ANDRADE, S.R.M. de. Reação a doenças e produtividade de um clone de maracujazeiro-azedo propagado por estaquia e enxertia em estacas herbáceas de Passiflora silvestre. Revista Brasileira de Fruticultura, Jaboticabal, v.28, n.1, p.97-100, 2006.

KIMURA, A. Estudo da enxertia hipocotiledonar de plântulas em Passiflora edulis Sims f. flavicarpa Deg. 1994. 56 f. Monografia (Graduação em Agronomia) - Faculdade de Ciências Agrárias e Veterinárias, Universidade Estadual Paulista, Jaboticabal, 1994.

KOSOSKI, R.M.; PEIXOTO, J.R.; JUNQUEIRA, N.T.V.; UESUGI, C.H.; MELO, B. Reação de genótipos de maracujazeiro-azedo a Xanthomonas campestris pv. passiflorae, em casa de vegetação. Bioscience Journal, Uberlândia, v.24, n.1, p.60-66, 2008.

LENZA, J.B.; VALENTE, J.P.; RONCATTO, G.; CHIG, L.A. Índice de pegamento e precocidade de mudas da variedade FB200 enxertada em diferentes espécies silvestres e comerciais de maracujazeiro. Revista Brasileira de Fruticultura, Jaboticabal, v.31, n.3, p.831-836, 2009.

MEDEIROS, A.M. de; PERUCH, L.A.M. Fungicidas e argila silicatada no controle da antracnose do maracujá-amarelo. Semina: Ciências Agrárias, Londrina, v.33, n.5, p.1803-1808, 2012. 
MENEZES, J.M.T.; OLIVEIRA, J.C.; RUGGIERO, C.; BANZATO, D.A. Avaliação da taxa de pegamento de enxertos de maracujá-amarelo sobre espécies tolerantes à "morte prematura de plantas". Científica, Jaboticabal, v.22, p.95-104, 1994.

NOGUEIRA FILHO, G.C.; RONCATTO, G.; RUGGIERO, C.; OLIVEIRA, J.C. de; MALHEIROS, E. B. Desenvolvimento e produção das plantas de maracujazeiro-amarelo produzidas por enxertia hipocotiledonar sobre seis porta-enxertos. Revista Brasileira de Fruticultura, Jaboticabal, v.32, n.2, p.535-543, 2010.

NOGUEIRA FILHO, G.C.; RONCATTO, G.; RUGGIERO, C.; OLIVEIRA, J.C. de; MALHEIROS, E.B. Produção de mudas de maracujazeiro-amarelo por enxertia hipocotiledonar sobre sete espécies de passifloras. Revista Brasileira de Fruticultura, Jaboticabal, v.33, n.1, p.237-245, 2011.

NOGUEIRA FILHO, G.C.; RONCATTO, G.; RUGGIEIRO, C.; OLIVEIRA, J.C. de; MALHEIROS, E.B. Propagação vegetativa do maracujazeiro-conquista de novas adesões. In: FALEIRO, F.G.; JUNQUEIRA, N.T.V.; BRAGA, M.F. (Ed.). Maracujá: germoplasma e melhoramento genético. Planaltina: Embrapa Cerrados, 2005. p. 340-358.

PINA, A.; ERREA, P. A review of new advances in mechanism of graft compatibility-incompatibility. Scientia Horticulturae, Amsterdam, v.106, n.1, p.1-11, 2005.

RONCATTO, G.; ASSIS, G.M.L. de; OLIVEIRA, T.K. de; LESSA, L.S. Pegamento da enxertia em diferentes combinações de variedades e espécies utilizadas como copa e como porta-enxertos de maracujazeiro. Revista Brasileira de Fruticultura, Jaboticabal, v.33, n.3, p. 948-953, 2011.
RONCATTO, G.; OLIVEIRA, J.C. de; RUGGIERO, C.; NOGUEIRA FILHO, G.C.; CENTURION, M.A.P. da C.; FERREIRA, F. R. Comportamento de maracujazeiros (Passiflora spp.) quanto à morte prematura. Revista Brasileira de Fruticultura, Jaboticabal, v.26, n.3, p.552-554, 2004.

SANTOS, C.A.C.; VIEIRA, E.L.; PEIXOTO, C.P.; BENJAMIM, D.A.; SANTOS, C.R.S. dos. Crescimento inicial de plantas de maracujazeiroamarelo submetidas à giberelina. Comunicata Scientiae, Teresina, v.1, n.1, p.29-34, 2010.

SANTOS, C.E.M.; PISSIONI, L.L.M.; MORGADO, M.A.D.; CRUZ, C.D.; BRUCKNER, C.H. Estratégias de seleção em progênies de maracujazeiro-amarelo quanto ao vigor e incidênica de verrugose. Revista Brasileira de Fruticultura, Jaboticabal, v.30, n.2, p. 444-449, 2008.

SAS INSTITUTE. SAS/STAT ${ }^{\circledR}$ 9.1. User's guide. Cary, 2004.

SILVA, M.M.; BRUKNER, C.H.; PICANÇO, M.; MOLINA-RUGAMA, A. Número floral, clima, densidad poblacional de Xylocopa spp. (Hymenoptera: Anthophoridae) y polinización del maracuyá (Passiflora edulis f. flavicarpa). Revista de Biología Tropical, San José, v.47, n.4, p.711$718,1999$.

SUASSUNA, T.M.F.; BRUCKNER, C.H.; CARVALHO, C.R.; BORÉM, A. Self-incompatibility in passionfruit: evidence of gametophytic-sporophytic control. Theoretical and Applied Genetics, Berlin, v.106, p.298-302, 2003.

TAIZ, L.; ZEIGER, E. Fisiologia vegetal. Porto Alegre: Artmed, 2004. 719 p.

WIDMER, A.; LEXER, C.; COZZOLINO, S. Evolution of reproductive isolation in plants. Heredity, London, v.102, n.1, p.31-38, 2009. 